(2002) Chapter for Ethical issues in maternal-fetal medicine ed Donna Dickenson Cambridge University Press, pages 195-212

\title{
Prenatal counselling and images of disability
}

Priscilla Alderson

Prenatal counselling and associated tests have become routine parts of prenatal care in many countries (Reid, 1990). The main intentions are to offer women the choice about whether to continue with a pregnancy when a fetus is impaired, and to contribute to reducing the incidence of disability with its attendant distresses and costs (HTA, 1998). This chapter reviews contrasting views about prenatal counselling, its advantages and disadvantages. Medical and counselling images of disability are compared with the views of adults who have conditions which are tested for prenatally. The evidence poses questions for bioethical reflection about the nature of disability (is it mainly physical impairment or social restrictions?) and about the possible impact of prenatal screening and counselling on maternal-fetal relationships. These questions include not only personal, mother-child relationships, but also the way that parenting generally, like pregnancy, may be becoming tentative and provisional, instead of unconditional acceptance of the child as a'a gift of God': common in traditional rhetoric, at least, if not in practice.

\section{Prenatal counselling}

Prenatal testing and counselling have expanded since prenatal diagnosis of Down's syndrome, thalassaemia and sickle cell anaemia disease began through amniocentesis in the late 1960s. Chorionic villus sampling (cvs), another diagnostic test which also draws fetal material from within the maternal abdomen, has since been developed. There are now two further and less invasive methods, which examine either serum from maternal blood tests or else, from about 12-15 weeks gestation, nuchal translucency (swelling in the fetal neck) by ultrasound scanning,. Both these tests can indicate higher risks of the fetus having a chromosomal disorder or spina bifida (Wald et al, 1992) and increasingly serum screening and ultrasound scanning are routinely offered in wealthier countries. In Britain, in areas with many members of ethnic minority groups affected by sickle cell anaemia or thalassaemia, universal prenatal screening for these conditions has been implemented or proposed. The monogenetic condition most likely to affect Caucasians, cystic fibrosis, is not yet routinely screened for, but, as with other monogenetic conditions, prenatal tests are often offered to families known to be affected. The tests may be preceded or followed by counselling, which ranges from giving medical results to detailed discussion about the nature and meaning of the tests, the results and the possible choices they offer (Green and Statham, 1996; Marteau et al., 1988).

There is a crucial difference in knowledge of the condition being tested for between people with an affected close relative who have personal experience and who opt-in to have prenatal tests, and the 'healthy' unaffected majority of pregnant women who are routinely screened unless they opt-out. The latter group is likely to need much more counselling before being able to make an informed choice about whether to have a test. Yet because personal opt-in testing involves far fewer people and tends to be done by clinical geneticists, whereas mass screening involves far more people and is 
done by generalist prenatal staff, the latter group usually receive much less counselling (Clarke, 1994, 1997).

Prenatal counselling can begin before conception, when people in a 'high risk' group or family are tested for their carrier status of single gene conditions. The same tests during pregnancy indicate, if both parents are carriers, that the fetus could be a carrier or have the full condition. So a positive result leads on to decisions about whether to have the more invasive definitive tests of amniocentesis or cvs, and whether to continue with the pregnancy.

\section{Advantages of prenatal counselling}

Advocates of universal prenatal screening and counselling say that the services offer every woman information and opportunities to choose. Preconceptual tests for carrier status may influence decisions about choosing a partner and becoming a parent. With fetal tests, parents may be more accepting of an impaired child if they are able to prepare emotionally before the birth, and are also able to feel that they chose to have the child rather than feeling imposed upon. Termination of affected pregnancies obviates the emotional, practical and financial costs of supporting disabled children, and also prevents the suffering which the child and family would otherwise endure. 'Therapeutic termination' is usually cited as the 'effective remedy' which validates screening programmes (HTA, 1998). Decades of preconceptual and prenatal screening in Cyprus have contained the costs of treating thalassaemia which would otherwise have overwhelmed the national budget (Modell and Kuliev, 1993).

Fetal tests and prenatal selection now enable women from families with a known severe genetic disorder to have healthy children, whereas previously they could only choose between either the risk of having an impaired child or else remaining childless. Efficient screening programmes involve the kinds of scientific and statistical knowledge which raise standards in evidence-based health services (Thornton, 1994) and also raise standards and the status of the nursing, midwifery and counselling professions (Sigmon et al., 1997).

The prenatal literature, confirmed by our research observations (see Acknowledgements), tends to emphasise the burdens of having an impaired child. For example, Professor Lilford calculates a net gain to society of screening 100,000 pregnancies, involving 3,000 amniocentesis (2,960 with negative results) incurring the inadvertent miscarriage of 30 unaffected fetuses, in order to reduce the incidence of Down's syndrome from 100 to 60 live births (Painton, 1997). He considers the costs are justified by the severity of Down's syndrome. There is frequent mention of 'risk', 'handicap', 'mental retardation', 'bad/faulty/dangerous gene', 'problem', 'trouble' and suffering' (see review by, for example, Shakespeare, 1999). Pathology tends to be stressed, rather than the unpredictable range from very mild to very severe. For example, a paper in a leading medical peer-reviewed journal begins, 'Spina bifida occurs in one of 2,000 births and leads to life long and devastating physical disabilities including paraplegia, hydrocephalus, incontinence, sexual dysfunction, skeletal deformities and mental impairment.'( Scott et al., 1998) 'Including' could imply that all cases with spina bifida have these and other defects, although the accurate meaning would be 'may include'; some people with spina bifida have none 
of these problems. However, by implication, the greater the costs of disability, then the greater the benefits of prenatal prevention.

Universal screening and counselling are guided by principles of respect for prospective parents' autonomy, the justice of fair distribution and cost containment, and the beneficence of preventing suffering and promoting scientific public health and other health services, as well as by reasoned utilitarian values (Bromham, Dalton and Jackson, 1990; Ettorre, 1999). The intention is to promote healthier and happier maternal-fetal and subsequent mother-child relationships.

\section{Disadvantages of prenatal counselling}

Concerns about prenatal testing and counselling range from the effects on individuals to broader social effects. Screening of large populations raises unnecessary anxiety among the vast majority of women whose pregnancies are 'normal', although many have to go through anxious waiting for ominous screening results to be clarified (Green, Statham and Snowden, 1994). Frequently, women are screened without their full knowledge or consent (Green, 1994; Marteau, 1995). Prenatal counselling services tend to be under-resourced and fall below recommended standards, so despite their best efforts staff seldom have enough time to counsel well (Clarke, 1994; Smith, Shaw and Marteau, 1994). The diagnostic fetal tests are risky. Amniocentesis and cvs each incur a one per cent risk of miscarriage, and some clinics warn that autopsies after termination find on average that one fetus in every 200 is 'normal' after a false positive result $(\mathrm{KCH}, 1999)$. False positive and false negative results are further complicated when risks and reassurance are misunderstood, and are reduced to statistical terms which confuse many women - and also many prenatal counsellors (Sadler, 1997; HTA, 1998). Pregnancy is being transformed from a healthy 'natural' experience into a pathological 'tentative' state in which women are increasingly bound by medical opinion, invasive surveillance and 'manufactured uncertainty' (Rothman, 1994, 1998). Despite being intended to prevent suffering, termination of pregnancy for fetal abnormality can cause intense distress and regret (Green and Statham, 1996; Santalahti, 1998).

New reproductive technologies align with other current trends, such as risk management, consumerism and economic pressures (Beck 1992; Winkler, 1998) to encourage women to expect to have f a 'perfect' baby, closer to a consumer commodity than a valued person with ordinary human failings. Some analysts see these trends as undermining the status and value of children (O'Neill, 1994; Brazier, 1996), others criticise them as 'feto-centric' (Rothman, 1996:26). Either way, there is a growing tendency to set the interests and rights of mother and fetus in opposition, as illustrated by Bromham et al. (1990). This conflict has been critically analysed by Callahan and Knight (1992) who show how, in cases of enforced Caesareans in the US, fetal distress has tended to be linked to maternal disadvantage. Better living standards and health care could benefit both mother and fetus, preventing occasions for conflicts of interests. Women who escaped from having enforced surgery tended to give birth normally, so questioning the medical expertise on which fetal rights arguments are based.

While women's lives are complicated by pregnancy, many women welcome pregnancy as personally fulfilling and status-enhancing - as demonstrated by the 
demand for infertility services. Yet during recent decades, universal prenatal screening has encouraged a tendency towards treating every pregnancy, however greatly desired, as provisional, creating a culture of 'Do you really want it? Take it or leave it.' The technologies contribute towards accentuating conflicts between maternal and fetal interests through their ability to scan and screen the fetus as a separate identity, and their emphasis on 'abnormality'. Decisions about 'therapeutic' abortion are treated as medically informed technical choices about 'handicap' rather than as moral decisions which profoundly affect human relationships, identity and obligations, and the meaning of parenthood as an unconditional or else a provisional relationship.

Further concerns include the following questions. Are women truly informed and respected, or are the choices they are asked to make illusory, overly constrained by economic and social pressures, or unwanted burdens for women who would prefer not to know or to choose? Economically, could the considerable funds and resources devoted to prenatal screening be used more effectively to prevent and treat disease and disability, which are far more commonly acquired than innate? (Oliver, 1996). How scientific can prenatal counselling be, given high rates of false positive and false negative results of initial screening, and the inability to assess how severely affected a fetus is, with the unknown impact of the potential child's future lifestyle?Although opt-in individual testing at the request of women who have affected relatives with a genetic condition is beneficial, there is a strong case for showing that mass prenatal screening causes more harm than good (Clarke, 1997).

\section{Disabled people's perspectives}

The pros and cons listed so far can all be based on mainstream medical and moral assumptions: that health and independent personal fulfilment are the highest goods; that it is therefore right to prevent and avoid illness and disability, to the extent of preventing disabled lives; that such lives inevitably will be costly, dependent lives of suffering; and that it is kind and responsible to the potential person and to the family, especially the mother, to relieve them of these burdens.

Yet these assumptions raise questions. What do disabled people think about the images of disability publicized by the screening services, and their effects on human relationships? Is life with the screened-for conditions inevitably so seriously impaired, dependent, sad and unproductive? What do people who live with these conditions think about the value and quality of their life and about prenatal screening? How do they feel when close relatives consider having an abortion of a fetus with their condition? The next two sections consider these questions, beginning with the activists' views.

\section{Radical views of disabled people}

Disability activists contrast the term 'people with a disability or handicap' with that of 'disabled people' (Oliver, 1996; Asch, 1999; Asch, 2000). They argue that the former phrase emphasises a deficit in the person, and the latter term denotes how they are disabled more by an uncaring society than by any impairment or learning difficulty (Goodey, 1991; Ward, 1997) they may have. Oliver, a professor who uses a wheelchair, argues that his mobility is limited by the poor design of local buses rather 
than by his physical state. Disability activists claim equal civil rights, access and opportunities with everyone else, and they oppose the discriminatory language of 'special need'. They criticise the medicalization of disability, saying that they wish to be treated by doctors when they are ill or injured or have a condition which can be cured or palliated, but not otherwise. Many disabilities are not susceptible to any medical treatment and, according to the activists, in cases when doctors cannot do good they can do harm, both to the individual and more generally by pathologizing disabilities. With other critical researchers, they challenge geneticization ( Lippman, 1991), its eugenic tendencies (Paul, 1992) and its fatalistic reductionism to genetic influences and away from social influences and human agency (Rose, 1995). Language blurs thought in general policies and individual practices. As Steinberg (1997:117) notes, talk of 'an "offending gene" implicitly bespeaks an "offensive person"”.

Shakespeare (1999) reviews openly eugenic and influential medical comments about screening services. Yet he asks whether both medical and activist images of disability are not 'losing the plot'. Perhaps they are equally extreme, one exaggerating pathologies, the other over-denying them, and neither attending to the lived realities of people's daily lives which, Lippman (1994) urges, should be examined carefully. Issues include women making responsible prenatal decisions, the goodwill of the staff who work with them, and the diverse and expert but little-known views of disabled people. Shakespeare tries to steer a middle course between the polarities of denial of the limitations of very severe disability, on the one hand, or else fearful pity and dread about very severe disability, on the other. Interviews to be described later consider how disabled people work between these polarities in their everyday realities.

Attempts to analyse maternal-fetal relations and prenatal decisions are trapped in another powerfully dismissive demarcation: pro-life versus pro-choice. All discussion is too easily assigned to one side or the other, with superficial approval or rejection. Yet decisions about a greatly desired though impaired pregnancy illuminate the complications in right-to-life arguments versus women's actual right to choose freely when they want neither available option - neither a severely impaired child nor an abortion.

Disabled feminists and other feminists discuss this middle ground (Degner, 1990; Morris, 1991; Asch, 1999; Asch, 2000). Crow (1996, p.208) says they should acknowledge that impairment, instead of being 'irrelevant, neutral and sometimes positive', really is a 'quandary' of 'contradictions and complexities'. Ramazanoglu (1989) argues that feminist research is a matter of examining and holding together contradictions instead of futile attempts to ignore or resolve them superficially, and this links to concepts of 'maternal holding on' watching and waiting (Ruddick, 1990; Adams, 1995) in contrast to 'masculinist' decisive rapid intervention which prenatal counselling tends to facilitate. The next section reviews a few of the responses of disabled people during our research interviews.

\section{Research with disabled people}

During a European project (see Acknowledgements) researchers investigated the views on prenatal screening of physicians, midwives, pregnant women, the general 
public, experts and reports in the mass media and professional journals. A small study also obtained the views of adults who have a condition which is screened or tested for prenatally. In the UK, we interviewed 40 people, ten each with cystic fibrosis $(\mathrm{CF})$, sickle cell anaemia or thalassaemia and five each with Down's syndrome or spina bifida.

Two aspects of the interviews provided information relevant to prenatal screening. The first, through general questions about their family and friends, education and work, problems, enjoyments and aims, built up a picture of interviewees' views on the quality and value, and the possible suffering and costly dependence of their lives. The second aspect was to ask interviewees directly for their views about being or becoming parents themselves and about prenatal screening choices. Did they agree with the assumption underlying screening policies that it is reasonable and perhaps preferable to prevent lives such as theirs?

Before reviewing some of the replies, a note about research method is necessary. As reviews of Medline and other website data-sets show, the medical literature on these conditions is mainly drawn from medical records and research about associated pathology, and from quantitative psychological surveys of anxiety, depression, intelligence and quality of life. The research relies on standardized questionnaires which measure levels of difficulty. Researchers use a slightly impersonal 'objective' manner in order to be fair and to elicit comparable replies from everyone. They focus on disability, asking questions such as 'How does your illness affect your daily life?' rather than considering other possible factors.

In contrast, we used qualitative methods, a less formal interview style, and open questions asking for detailed replies; we looked for variety instead of measuring common factors. We contacted small groups of people through informal networks in order, we hoped, to avoid seeming perhaps intimidatingly professional, and to stress that we saw them as persons rather than patients. For terms such as 'patient', 'disease' and 'suffering', we substituted the more neutral ones of 'person', 'condition' and 'experience'. With each potentially negative question about problems or difficulties, we also asked a positive one about rewards and successes. Everyone was sent a leaflet before they agreed to take part about the topics we would raise, and about their rights: to consent or refuse, to withdraw or withhold information, and to maintain confidentiality. We were worried at first about whether we should risk asking questions which might be painfully probing, but we were soon reassured by the responses; almost everyone talked calmly and frankly as if they were used to discussing issues such as screening for their condition. Most taped interviews lasted about an hour; towards the end we said that, although we would like to use all the detail which interviewees had supplied in our reports, we would have to select and summarize their comments for published papers. We asked interviewees to help us to complete summary sheets, noting their key responses to each main topic in a few sentences. This worked very well, as the previous discussion had helped to order and clarify their views, and the sheets gave them some editorial control over how we would use their views.

In contrast to mainstream medical and psychological traditions, our approach, methods and language yield different and, we would argue, more realistic insights into the daily lives of people with serious congenital conditions. Table 1 summarizes the 
background detail of the numbers of men and women interviewed, their ages, education, employment and households. Cohabitation was higher than shown in the table because some had formerly lived with partners. Table 1 shows that most of interviewees contribute, now or in the past, by doing paid work instead of incurring the 'lifetime costs of care' which are used in some calculations to show that prenatal screening is cost-effective (Wald, 1992). All the interviewees are literate and numerate: two groups are highly educated, five people with $\mathrm{CF}$ had been to university and two more planned to go there. The groups also did a great deal of voluntary work. Among the people with Down's syndrome, for example, one helped to run a youth club, one taught on courses about empowerment, assertion and safe sex for people with learning difficulties and was an artist, and two were actors who shared in creating plays about disability and genetics. All the interviewees related a wide range of activities which they enjoyed doing.

This is not to claim that these interviewees are representative. Too little social research has been conducted to discover what a representative group with, say, sickle cell anaemia would be like. Qualitative research such as this study cannot produce measurable, generalisable findings about the abilities and experiences of these five groups of people. Yet the study can challenge general assumptions, by showing how these interviewees did not fit the negative images propounded in the prenatal medical literature. To give a flavour of the interviews, the next sections will describe a few of them.

\section{Examples from the interviews}

To give an example of the informality, my first interview about cystic fibrosis was with Tim, aged 23 (names have been changed). I was worried when he showed me into the family living room where his sister and girl friend were already sitting, as I expected that their presence would inhibit him. I avoid the standard research practice of asking families to regroup to allow for a private interview, partly because their decisions and family dynamics are such useful data, partly because I would assert a potentially inhibiting power balance. The point of meeting at their home or other place of their choice is to respect their status: they are the experts who are helping me. Tim could have arranged a private meeting if he had wanted to. During the interview he spoke about his shorter life expectancy, and when the young women objected he said that they always avoided the subject, but he wanted to talk about it with them. I was pleased that he seemed to use the interview for his own purposes, and their presence was a spur to talk rather than a constraint. Tim worked as a retail manager, and used his days off to attend hospital. Like other interviewees he tried to make his employment record at least as good as that of his colleagues, to prevent his condition being used as an excuse to dismiss him. In common with other people his age, Tim longed to earn enough to live with his girlfriend and leave his parents' home. Like many of the interviewees, when asked about his hopes and aims, Tim spoke freely about being a partner and becoming a parent, spontaneously raising these issues and relieving me of the worry that I might upset or embarrass him by introducing them.

Some of the people with CF had successful careers. Jane was delighted to return to work and to caring fully for her family after her recent heart transplant, but others were frustrated at not being able to find suitable work. They found it hard to live on 
benefits in cold damp homes, unsuitable for their lungs. Life expectancy for many people with CF is now over 40, but they felt that out-dated images of the sickly child who dies young are still too prominent and deter employers from accepting them.

To illustrate the range of people, the most disabled person with $\mathrm{CF}$ was Jenny aged 24, who wished that she could use her English degree to be a journalist. Having returned to live with her parents, she would 'like to be able to do things more spontaneously, have more energy, spend less time with my parents and have more self-identity, be stronger and more confident'. She sang and composed, and like several others enjoyed clubbing but found the smoky atmosphere a problem. Her boyfriend helped her to do her daily chest physiotherapy. Jenny said that she would love to be married and have chldren but felt that no one would want to take on the responsibility of caring for her and that she was not strong enough to have a child. She was unusual among the group in speaking of her pessimism and depression, but like all of them she distinguished between problems attributable to $\mathrm{CF}$ and problems attributable to other factors such as lack of transport and suitable employment. Asked what she might say to a woman who has been told that the baby she is expecting has $\mathrm{CF}$, Jenny replied, 'I would say have the child because I would much rather be alive than not, and nowadays treatment is good. Twenty years ago maybe I would have said no. A baby now with CF has much better chances than I have.' Jenny's family did not talk much about her shorter life expectancy. 'I'm glad of that and I don't dwell on death and illness. I just get on with doing what I want to do.' In contrast, Rob, aged 26, regrets being told 'practically since I was born that I might die soon. It has stopped me from making plans and getting on with my life, like going to university or doing things which might be boring for a few years but lead on to something better.' When asked what he found helpful in his life, Rob talked, like several others, about being independent and inter-dependent rather than dependent. Asked what he might want to change about himself, again like some of the others Rob replied, 'I'm happy with my character, I'm very happy with what's happening in my life at the moment,' and he was more keen to talk about how to change society: 'I'd rip it up and start again, the materialism and back-biting and callousness. If that was sorted out, the smaller issues of tolerance and intolerance would drop into place.' Everyone spoke in many different ways about discrimination and intolerance of disability being the main social problems they would change. For example, one man with Down's syndrome described being pushed and shoved in the street by his neighbours, and another was fed up with being treated by new work colleagues as if he were stupid, though he added, 'They learn in the end, and then they realize that are the ones who look silly'.

The ten people with thalassaemia and ten with sickle cell anaemia experienced the hidden disability of chronic illness like the $\mathrm{CF}$ group. Sometimes they have crises which require hospital treatment. They too described a range of rewarding and frustrating experiences, enthusiasms and problems. Their conditions did not appear to dominate their lives in most cases, and much time was spent talking about the many things they had in common with their 'ordinary' peers: work or unemployment, income, housing, relationships, leisure activities and ambitions.

The five people with spina bifida showed the lack of correlation between physical disability and social fulfilment. Angela, who became upset during the interview and 
cried though she said she wanted to continue talking, was the least physically disabled one. In her mid-30s, she worked in a shop, where few of her colleagues knew she had any disability. She was actively involved with church and other groups, but said she wished that she had more friends and a boy friend. The other more disabled people with spina bifida included a young single mother who was also a college student, and Richard and Vivian who both used wheel chairs. Richard was a keep fit enthusiast who worked at a sports centre and planned to go to Australia to see the paralympics. He enjoyed going to city clubs with friends, and could haul himself in his chair up and down stairs, so he used underground trains despite officials trying to stop him. He said that when he joined mainstream secondary school, the wheelchair users were all taught mobility and coping with stairs and pavement kerbs, which helped him to become very fit. He said, 'I see myself as able-bodied as anyone else.'

Vivian's spine was too severely curved for surgical correction to be possible. We sat on the floor in her flat and she constantly shifted her weight to relieve her pain. She worked in journalism and also gave expert advice about access to public buildings. She passionately believed in and worked for disabled people's rights. Much of Vivian's income went on her transport costs and domestic help. Like Richard she had a very busy social life 'I'm a great one for socialising. You do feel low and in pain and angry with people and it is important to have friends and to go out for a drink.' and she talked enthusiastically about her many interests. Vivian was planning to have a baby and she talked of her mixed feelings about taking folic acid to reduce the risk of the baby having spina bifida, yet 'being proud that I have spina bifida' because it had given her such experience, knowledge and opportunities she would not otherwise have had.

The forty respondents' views on prenatal screening ranged from believing that it was very useful, to unhappiness that it was offered to anyone. Those with thalassaemia, sickle cell anaemia and CF were more likely favour screening, provided it was accurately informed about their condition, which they tended to doubt was the case. They also tended to say that they would respect any decision made by prospective parents after being properly informed, whether to continue or end a pregnancy affected by their condition, though they hoped it would continue and some had mixed feelings. One woman with CF said, 'CF doesn't do any good, but people with CF do. I'm angry that people assume abortion is advisable for CF or Down's but I respect the right of each person to choose in their own case. I'm not sure that many can make informed decisions....It's difficult, it's expensive and wasteful to test everyone, and if these scary policies come about, what kind of world would it be? Would anyone have babies?'

Many spoke eloquently about the dangers and hurt to them of discrimination, and the crucial importance of respect for every type of person. These views perhaps led them to be non-judgmental of other people, including the prenatal decisions they make. However, the people with Down's syndrome or spina bifida, conditions which are most routinely screened for, tended to be more unhappy about screening. For example, two men with Down's syndrome who had been talking intently about their acting, suddenly looked very sad when asked about screening, and said they did not want to talk about it, as if the subject was too painful. They knew about screening, having created plays relating to it. 


\section{Discussion}

The research could be criticized for being too homogeneous about widely diverse conditions. However, the interviewees had far more similarities than differences, including the ways they reflected on their lives, and their belief that they suffered from the general stigma of disability more than from their actual condition. Perhaps these interviewees are unusually healthy and capable for people with their conditions. Yet even so, there are probably many other people like them, living as actively as they do with their condition. This raises questions about why the prenatal literature, policy makers and counsellors make so little mention of the potential range of each condition from mild to severe, of the increasingly effective treatments which Jenny mentioned, and of the possibility that some therapeutic abortions may prevent potentially rewarding lives. A further complication for prenatal predictions is the mismatch, shown particularly by the people with spina bifida, between the degree of severity of physical disability and the way people value and enjoy their life.

\section{The implications of the interviews for prenatal counselling and maternal-fetal relations}

The overall impression given by the interviewees was of very interesting, thoughtful and pleasant people. Most of them appeared to value and enjoy their lives, sometimes despite pain and serious illness, as much as any average group of 40 young adults might say they do. One man with sickle cell anaemia was in such pain that his interview took place over three separate visits, but this was because he was so keen to take part. Their friends appeared to value them, and so did their families, with one exception as might be expected in any group of 40 adults (her mother had died and her father had remarried). Most interviewees had far more in common with their 'ordinary' peers than differences, and none showed any clear reason why their life would have been better prevented.

One woman with CF commented, 'I feel up today because I'm talking to you, and I'll feel down on another day.' Yet she also spoke frankly about her problems and fears, as well as about things she enjoyed. Even allowing for the artificial nature of the research interview, and the way our methods partly shape the evidence, as is inevitable in every type of research, the interviewees provide compelling evidence for questioning the assumptions on which prenatal policies and counselling are based: that it is reasonable to prevent such lives. The interviewees challenge the view that it is kinder to terminate any affected pregnancy, however mildly the fetus might be affected, because life is so awful for the severest cases.

Repeatedly, interviewees spoke of the crucial importance to them of being involved in mainstream society - schools and colleges, homes and jobs, clubs and pubs and friendships. They tended to find exclusion, rejection and prejudice more painful and disabling than the direct effects of their condition. Some saw rejection as a linked, indirect effect of their condition, but then another more impaired person would talk of overcoming a similar difficulty. They tended to stress their need to see beyond their condition as a personal predicament, and to press for greater inclusion by challenging negative attitudes in society, and by showing how they could be involved. They were 
grateful to parents who encouraged them to be strong and who, as one woman with Down's syndrome said of her mother, were ready to 'fight for my rights [even through] the High Court, the High Court of Justice!'

Several interviewees were concerned that prenatal counselling could be seen as official medical endorsement of prejudice against them, condoning the restrictions they most wanted to see removed from education, employment and their neighbourhoods. Some of them helped to train medical students, and they criticised inaccurate medical images of disability, such as the sickly child advertisements which raise funds for medical research. Our research aim was to listen to and report seldomheard voices, and here are some comments made by people with spina bifida.

- 'We're disabled by attitudes and lack of access' said Vivian.

- Angela said that 'parents should accept their child on any terms.'

- On prenatal screening, Vivian commented, 'You can't decide for people who haven't had their lives yet.... and I'd rather be alive than dead. I'm really proud of having spina bifida, it's not like AIDS or cancer [which her mother had died of]....It's made me make a real effort to do lots of things and to take risks....I don't need to be cured and I don't want to be anybody else.... You can't just get rid of people and go back to the Nazis.'

- Christel felt that she had become more mature than her friends through becoming a mother: 'Having a baby wisens you up'.

- Richard believed, 'If you're old enough to decide you want a child, you should be old enough to handle the child, no matter what disability or ability....If [a child] is going to have parents that care for it, then I don't think that it should need screening....I think the counselling is partly driven by ignorance.' If spina bifida is diagnosed prenatally, 'I would say, "keep the baby, try and make the most of it because there are ways round things.'

Richard was referring to a theme that ran through the interviews: of adaptation, ingenuity and a resilience that grows through accepting and surmounting difficulties. This is in contrast to prenatal screening policies which propose efforts to prevent and avoid difficulties, as if human beings cannot or should not have to experience them, and as if disability is not inevitable for most human beings, at least at the beginning and end of life. The interviewees quoted earlier suggest that this approach is unrealistic, because ordinary people's lives so often involve problems - such as with relationships, loss, frustrating limitations or poverty. Fearful avoidance of disability, rather than promoting ways to support disabled people's lives, is liable to diminish people rather than freeing them into new achievement and confidence.

The interviewees also worried about future trends, These are vividly illuminated by the consultation document on pre-implantation genetic diagnosis, PGD (HFEA, 2000; King, 2000), which is considered in the final part of this chapter. PGD involves genetic testing of embryos at about the eight-cell stage, after in vitro fertilization (IVF) and before selected embryos are implanted into a uterus. The HFEA asks which criteria should be used to decide when PGD may be appropriate, such as expectancy of a very short life, a life of very poor quality, or one of great suffering. The difficulty in these criteria is the current limitations in predicting how severe an impairment might be or might become, how much it may be ameliorated by social or medical 
support, and how the affected person and family may experience similar difficulties either as much hardship and suffering or as part of a worthwhile rewarding life. Some parents value their child's very short life far more than no life at all (Delight and Goodall, 1990). Quality of life fluctuates greatly for many people, and suffering is especially hard to gauge in people with severe mental impairments and those who appear to be unaware and unable to relate, which are further proposed criteria for using PGD. Unawareness may include unawareness of suffering, which would obviate the criterion of suffering, and uncertainty again prevails over the diagnosis and prognosis of unawareness. Children who have been dismissed as 'vegetables' are perceived by others to experience profound feelings, such as by the researcher who commented, 'Cabbages do not cry' (Oswin, 1971).

Apart from difficulties in deciding when to resort to PGD, there are broader concerns that PGD adds to the medical and state-funded prenatal screening technologies, in appearing to endorse discrimination against impaired people as unwanted burdens who are better excluded from society. The argument that prenatal selection is different from ending such lives after birth, and affects attitudes towards impaired fetuses only, is unconvincing. The interviewees show that some disabled people feel threatened and disadvantaged by the prejudices which are, perhaps inadvertently, promoted through prenatal screening. The emphasis on particular impairments when selecting an embryo or fetus as worth preserving suggests that any policy difference between preserving an embryo or a person with, say, thalassaemia is not one of principle but of practicality. Abortion is permissible and euthanasia is not, and people with thalassaemia are able to assert that their life is worthwhile. Babies and young children are in a vulnerable position between fetus and 'independent viable person'. Rather than justifying the view that parents' attitudes will be unaffected by screening and PGD programmes, perhaps it should be the responsibility of those who wish to introduce the programmes to guarantee that attitudes are not being affected. Social exclusion, school exclusion and family exclusion (in numbers of teenagers living on the streets) are increasing rapidly, as are expectations that children should conform to ever more specific milestones, school tests and behaviour standards with an unjust 'zero-tolerance' which does not allow for contingencies and disadvantages. Prenatal programmes are not responsible for these changes, but they are part of them, and are powerful medical and official indirect endorsements of them.

Another theme of injustice is when public rejection, expressed through national prenatal programmes, is made to appear to be a matter of private grief and responsibility, as when each individual woman faces the 'choice' of termination of pregnancy, a choice constrained by social and economic circumstances. Disabled activists refuse to accept this way of reducing the political to the personal, in individuals' 'triumph or tragedy stories' (Oliver, 1996). Yet pregnant women seldom question the way prenatal health professionals tell these stories, and describe certain impediments as incompatible with a reasonable life style. For this reason, some commentators urge that PGD and similar services should only be offered to affected families who specifically request such tests, and not to the general population. They are concerned that technological imperatives, free-market economics, and medicolegal defensiveness will ensure that PGD soon develops into a mass service, as IVF comes to be performed more easily and safely. Given a few embryos, tests which screen 'negatively' for one or a few specific impairments are soon likely to become 
multi-package tests to screen simultaneously for numerous impairments, and then tests to select 'positively' for growing numbers of preferred features such as intelligence of height. 'Non-directive' counselling of pregnant women about whether to keep a fetus differs from simply informing pre-pregnant women about which fetus they might prefer to acquire. The same questions can appear to be far less connected with morality or the responsibility of mother to child. Gradually, technology reframes and distances moral choices and the most intimate relationships. When the embryo and fetus, and implicitly the baby and child, are presented to women by health professionals as a means of fulfilling adults' dreams of perfection, rather than as ordinarily imperfect mortals to love as ends in themselves, then maternal-child as well as maternal-fetal relationships are likely to become ever more tentative and conditional.

\section{Acknowledgements}

This chapter draws on sociological research funded by the European Commission, Prenatal Screening in Europe Project no. 11 BMH4-CT96-0740, 1996-1999; by the Finnish Academy, 1998-1999; and by the Wellcome Bioethics Programme, 19992001, Cross Currents in Genetics Towards the Millennium. I am grateful to everyone who took part in the research, and to my co-researchers, although I am responsible for any shortcomings and opinions in this chapter.. 
Table 1. The 50 interviewees

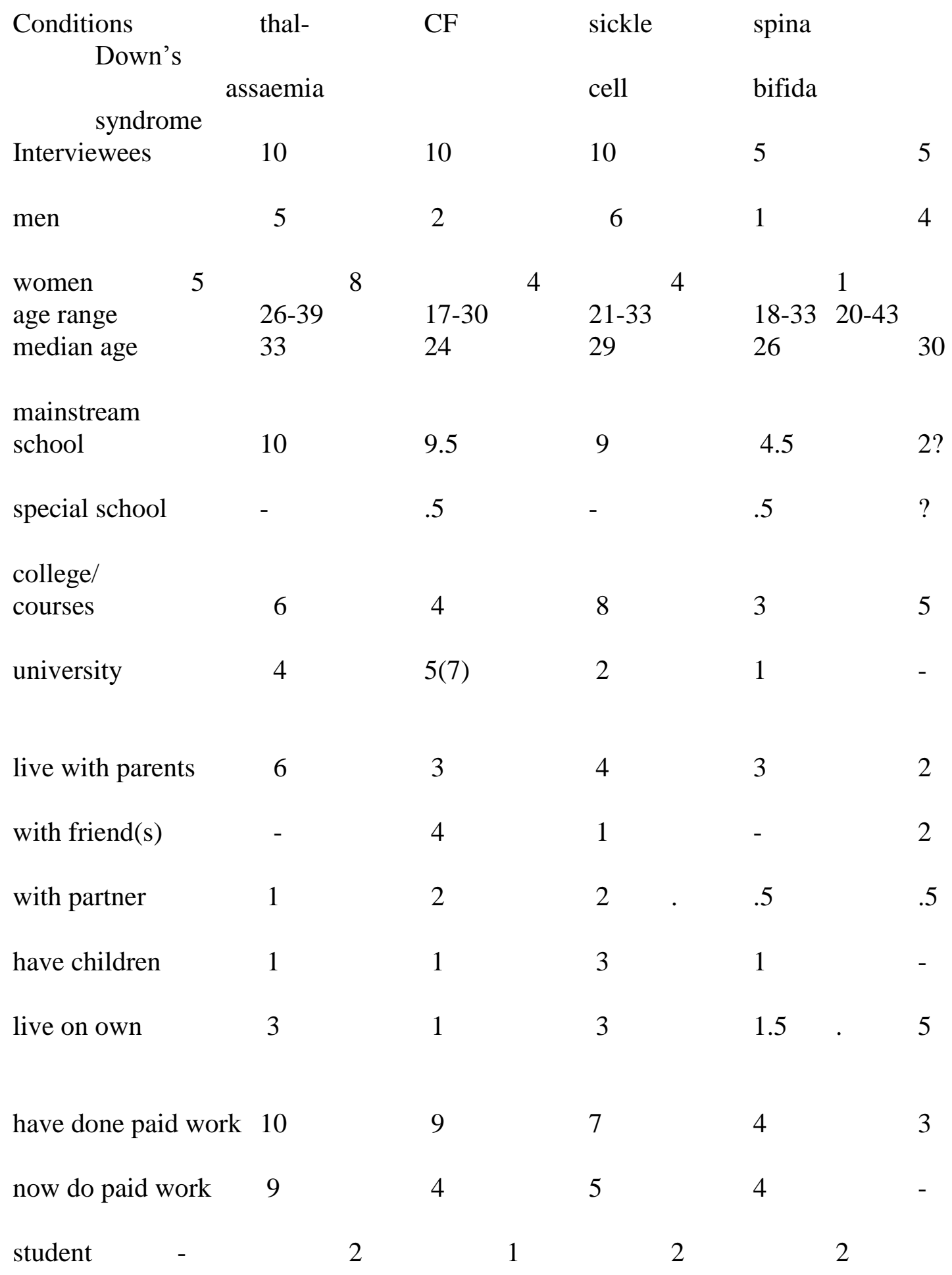




\section{References}

Asch, A. (1999). Prenatal diagnosis and selective abortion: a challenge to policy and practice. American Journal of Public Health, 89, 1649-57.

Asch, A. (2000). Why I haven't changed my mind about prenatal diagnosis: reflections and refinements. In Prenatal Testing and Disability Rights, eds. E. Parents and A. Washington: Georgetown University Press.

Beck, U. (1992). The Risk Society: Towards a New Modernity. London: Sage. Brazier, M. (1996). Embryos, property and people. Contemporary Reviews in Obstetrics and Gynaecology, 8, 50-53.

Bromham, D., Dalton, M. and Jackson, J. (eds.) (1990). Philosophical Ethics in Reproductive Medicine. Manchester: Manchester University Press.

Callahan, J. and Knight, J. (1992) Women, fetuses, medicine and the law. In Feminist Perspectives in Medical Ethics, ed. H. Holmes and L. Purdy, pp. 224-39. Indianapolis: Indiana University Press.

Clarke, A. (1994). Introduction to Genetic Counselling: Practice and Principles.

London; Routledge.

Clarke, A. (1997). Prenatal genetic screening: paradigms and perspectives. In

Genetics, Society and Clinical Practice, ed. P. Harper and A. Clarke, pp 119-40.

Oxford: Bios.

Crow, L. (1996). Including all our lives: reviewing the social model of disability. In

Encounters with Strangers: Feminism and Disability, ed. J. Morris. London: The

Women's Press.

Degener, L. (1990). Female self-determination between feminist claims and "voluntary" eugenics, between "rights" and ethics. Issues in Reproductive and Genetics Engineering, 3,87-99.

Delight, E., and Goodall, J. (1990) Love and loss: conversations with parents of babies with spina bifida managed without surgery. Developmental Medicine and Child Neurology, 61, 32, no. 8.

Ettorre, E. (1999). Experts as storytellers in reproductive genetics: exploring key issues. In The Sociology of the New Genetics., ed. P. Conrad and J. Gabe, pp.539-59. Oxford: Blackwell Sociology of Health and Illness Monograph Goodey, C. (1991). Living in The Real World: Families Speak About Down's Syndrome. London: The Twenty One Press.

Green, J. (1994). Serum screening for Down's syndrome: experiences of obstetricians in England and Wales. British Medical Journal, 309, 769-72.

Green, J., Statham, H. and Snowdon, C. (1994). Pregnancy: A Testing Time. Report of the Cambridge Prenatal Screening Study. Cambridge: Centre of Family Research. Green, J and Statham, H. (1996). Testing pregnancy. In The Troubled Helix, ed. T. Marteau and M. Richards., pp. 140-63. Cambridge: Cambridge University Press. HFEA (Human Fertilisation and Embryology Authority). (2000). Consultative Document on Pre-Imlantation Genetic Diagnosis. London: HFEA.

HTA -( Health Technology Assessment). (1998). Antenatal Screening for Down's Syndrome. vol, 2. no. 1. Southampton: HTA.

KCH -(King's College Hospital). (1999). Information Leaflet on Antenatal Screening. London: $\mathrm{KCH}$.

King, D. (2000). Response to the HFEA Consultative Document on Pre-Implantation Genetic Diagnosis. London: CAGHE. 
Lippman, A. (1991.). Prenatal testing and screening. American Journal of Law and Medicine, 17: 15-50.

Lippman, A. (1994). Prenatal testing and screening: constructing needs and reinforcing inequalities. In Introduction to Genetic Counselling: Practice and Principles, ed. A. Clarke, pp.142-86. London: Routledge.

Marteau, T. (1995). Towards informed decisions about prenatal testing: a review.

Prenatal Diagnosis, 15, 1215-26.

Marteau, T., Johnson, M., Plenicar, M., Shaw, R. and Slack, J. (1988). Development of a self-administered questionnaire to measure women's knowledge of prenatal screening and diagnostic tests. Journal of Psychosomatic Research, 32,403-8.

Modell, B. and Kuliev A. (1993). A scientific basis for cost-benefit analysis of genetic services. Trends in Genetics. 9,46-52.

Morris, J. (1991). Pride Against Prejudice. London: The Women's Press.

Oliver, M. (1996). Understanding Disability: from Theory to Practice. Basingstoke:

Macmillan.

O'Neill, J. (1994). The Missing Child in Liberal Theory. Newfoundland: University of Newfoundland Press.

Oswin, M. (1971). The Empty Hours. Harmondsworth: Penguin.

Painton, D. (ed.) (1997). Antenatal Screening and Abortion for Fetal Abnormality:

Medical and Ethical Issues. London: Birth Control Trust.

Paul, D. (1992). Eugenic anxieties, social realities and political choices. Social

Research, 59,663-83.

Ramazanoglu, C. (1989).Feminism and the Contradictions of Oppression. London:

Routledge.

Reid, M. (1990). Prenatal diagnosis and screening. In The Politics of Maternity Care, ed. J. Garcia, R. Kilpatrick and M. Richards, pp. 300-24. Oxford: Clarendon Press.

Rose, S. (1995). The rise of neurogenetic determinism. Nature, 373:380-82.

Rothman, B. K. (1994) The Tentative Pregnancy: Amniocentesis and the Sexual

Politics of Motherhood. London: Pandora.

Rothman, B. K. (1996) Medical sociology confronts the human genome. Medical

Sociology News, 22, 23-35.

Rothman, B. K. (1998). Genetic Maps and Human Imagination. New York: W. W.

Norton.

Ruddick, S. (1990). Maternal Thinking: Towards a Politics of Peace. London: The

Women's Press.

Sadler, M. (1997). Serum screening for Down's syndrome: how much do health professionals know? British Journal of Obstetrics and Gynaecology, 104,176-9. Santalahti, P. (1998). Prenatal Screening in Finland. Helsinki: STAKES.

Scott, N., Adzick, L., Sutton, L., Crombleholme, T. and Flake, A. (1998) Successful fetal surgery for spina bifida. Lancet, 352,1675-6.

Shakespeare, T. (1999). Losing the plot? Medical and activist discourses of contemporary genetics and disability. Sociology of Health and Illness, 21,:669-88.

Sigmon, H., Grady, P. and Amende, L. (1997). The National Institute of Nursing explores opportunities in genetics research. Nursing Outlook, 45,215-9.

Smith, D., Shaw, R.and .Marteau, T. (1994) Informed consent to undergo serum screening for Down's Syndrome: the gap between policy and practice. British Medical Journal 309,776.

Steinberg, D. (1997). Bodies in Glass: Genetics, Eugenics and Embryo Ethics. Manchester: Manchester University Press. 
Thornton, J. (1994). Genetics, information and choice. In Consent and the New Reproductive Technologies, ed. P. Alderson, pp. 35-51. London: Institute of Education.

Wald, N., Kennard, A., Densem, J., Cuckle, H., Chard, T. and Butler, L. (1992) Antenatal maternal serum screening for Down's syndrome. British Medical Journal, 305, 391-3.

Ward, L. (1997). Practising partnership: involving people with intellectual disabilities in research. In Disability Discourse: Research, Public Policy and Human Rights, ed. M. Bach and M. Rioux. Ontario: Roeher Institute.

Winkler, M. (1998.) The devices and desires of our own hearts. In Enhancing Human Traits: Ethical and Social Implications, ed. E. Parens, pp. 238-50 Washington DC: Georgetown University Press. 